\title{
Violencia de género y ciudad: cartografías feministas del temor y el miedo ${ }^{1}$
}

\author{
Gender Violence and City: Feminists \\ Cartographies of Fear and Dread
}

\section{Violência de gênero e mapas feministas da cidade e do medo}

\author{
Juliana Toro Jiménez $z^{2}$ \\ Investigadora del Grupo de Investigación Cultura, Violencia y Territorio del INER \\ Universidad de Antioquia, Medellín, Colombia \\ juliana.toroji@gmail.com

\section{María Ochoa Sierra ${ }^{3}$} \\ Investigadora del Grupo de Investigación Cultura, Violencia y Territorio del INER \\ Universidad de Antioquia, Medellín, Colombia \\ maria.ochoas@udea.edu.co
}

Recibido: $15 / 05 / 2016$

Aprobado: $28 / 10 / 2016$

1 Este artículo es producto del trabajo de grado de Juliana Toro Jiménez, asesorado por María Ochoa, para optar al título de antropóloga. El proyecto se titula: Mujeres, a la calle: configuraciones urbanas, violencia y roles de género. Un análisis de las violencias hacia las mujeres en espacios públicos de Medellín.

2 Antropóloga.

3 Socióloga, Magíster en Ciencia Política. 


\title{
Resumen
}

El artículo reflexiona alrededor de las preguntas ¿Cuáles son las violencias de género en el espacio público en la ciudad de Medellín? ¿De qué manera influyen las violencias hacia las mujeres y los roles de género en la apropiación y configuración de los espacios públicos de la ciudad? A través de búsquedas en la prensa, encuestas, grupos focales, historias de vida y cartografía social, se hace un retrato con perspectiva de género de la ciudad. En dicho retrato se da cuenta de los lugares temidos, los lugares prohibidos, y las prácticas y vivencias de las mujeres; así como de sus imaginarios, sus miedos, expectativas y frustraciones sobre su apropiación del espacio público.

Palabras clave: acoso sexual; violencia sexual; espacio urbano; estudios sobre las mujeres.

\begin{abstract}
The article ponders upon which are the gender violence in the city of Medellin' public space; and how violence against women and gender roles influence in ownership and configuration of the city' public spaces. A portrait of the city from a gender perspective is made through: press research, surveys, focus groups, life stories and social cartographies. In order to identify the feared and forbidden places, women's practices and experiences; as well as their imaginaries, fears, expectations and frustrations on their appropriation of public space.
\end{abstract}

Keywords: Sexual abuse; sexual violence; urban spaces; women studies.

\section{Resumo}

$\mathrm{O}$ artigo reflete sobre as seguintes questões: quais são as violências de género no espaço público na cidade de Medellín? Como a violência influencia as mulheres e seus papéis de gênero na apropriação e configuração de espaços públicos da cidade? A partir de revisão de imprensa, enquetes, grupos focais, histórias de vida e cartografia social, se faz um retrato da cidade com perspectiva de gênero, dando conta dos espaços temidos, proibidos assim como das práticas, vivencias, imaginários, medos, expectativas e frustrações de mulheres na sua apropriação do espaço público.

Palavras-chave: assédio sexual; violência sexual; espaço urbano; estudos sobre as mulheres. 
Cuando uno caminaba por la carretera, porque a veces el andén estaba ocupado [...] y yo iba con una compañera o iba sola también, pasaban muchachos en bicicleta y también le agarraban la nalga a uno y salían velozmente, se iban corriendo en esa bicicleta, y [...] cuando uno iba con una amiga o algo, nadie se quería poner del lado más externo de la carretera (Tatiana Anillo, grupo focal mujeres, 2 de abril de 2015).

\section{Introducción}

Múltiples violencias hacia las mujeres tienen como escenario los espacios públicos de la ciudad. Violencias de alto impacto y violencias sutiles y cotidianas que refuerzan en las mujeres sentimientos de temor e inseguridad como instrucción formativa y adaptativa, adquiridas como aprendizajes de socialización primaria y que en la vida adulta pueden tener consecuencias como la limitación de libertades y derechos como ciudadanas.

En Colombia los esfuerzos se han concentrado en solucionar la violencia intrafamiliar, enfocándose en los espacios privados y dejando a un lado el análisis de las violencias y amenazas hacia las mujeres en espacios públicos de la ciudad. Las instituciones estatales encargadas de operar los estudios, proyectos y normas para prevenir y reducir la violencia contra las mujeres han centrado sus esfuerzos en la violencia intrafamiliar, tal y como aparece en los Lineamientos de la Política Pública Nacional de Equidad de Género para las mujeres (Alta Consejería Presidencial para la Equidad de la Mujer, 2012). Esta visión circunscribe la violencia de género al espacio privado por su magnitud y las implicaciones de vivir con los agresores, pero oscurece la que acontece en los espacios públicos, donde diariamente se presentan agresiones hacia las mujeres por razones de género. Es poca la información que se encuentra sobre lo que ocurre en estos escenarios, ya que se cuenta con escasos estudios, noticias y estadísticas diferenciadas sobre el tema o cuando existen, su objetivo se centra en analizar las agresiones de pareja o las violencias más evidentes, incluyendo únicamente los casos de agresiones físicas, violación y feminicidios (que generalmente se nombran como homicidios y se disipa la violencia de género), dejando por fuera otros tipos de violencias sutiles.

Los espacios públicos de las ciudades son percibidos por la mayoría de las mujeres como amenazadores y atemorizantes. Esos temores se encuentran determinados por la poca familiaridad y confianza que sienten cuando circulan en determinados espacios urbanos; además, responden a construcciones culturales e históricas de ese "ser mujer", que ahondan sentimientos de inseguridad y autoprotección e introducen y refuerzan la mirada de vulnerabilidad hacia las mujeres (Falú, 2009).

La violencia de género obedece a una discriminación de carácter sexista que da cuenta de la desigualdad y de la dominación de un sujeto sobre otro, perpetuada gracias a un sistema de creencias que delimitan lo que hace un hombre

4 Para profundizar estos temas puede consultarse a Falú (2009); Niño (2000); Román (2009); Toro y Ochoa (2015). 
y lo que hace una mujer. Su carácter estructural hace que sea una forma de violencia permitida en las relaciones de pareja e intrafamiliares, pero también en el espacio público ${ }^{5}$. Este tipo de violencia es producto de la dominación masculina instaurada como habitus, a la vez aceptado y naturalizado, basado en una visión androcéntrica que aparece como neutra, pero que divide las cosas y las actividades en un sistema de oposiciones: masculino, femenino (Bourdieu, 1998).

Teniendo en cuenta lo planteado surge la necesidad de indagar por la relación entre las mujeres, la violencia de género y el espacio público, tomando como estudio de caso la ciudad de Medellín. En este sentido, considerando que las mujeres jóvenes son las más violentadas se procedió a la realización de 50 encuestas a mujeres en un rango de edad entre los 16 y los 36 años. La población encuestada estaba conformada, casi en su totalidad, por estudiantes y trabajadoras, con niveles de formación de secundaria y profesionales; solo cinco amas de casa, una desempleada y una activista y la mayoría de ellas habitantes de viviendas estrato $3(54 \%)$. Si bien la mayor parte de las encuestadas fueron estudiantes y trabajadoras, esto no es representativo en cuanto a la totalidad de oficios desempeñados por las mujeres en la ciudad, pero sí da cuenta de las características de una población de mujeres que desarrollan actividades en el espacio público. Si las encuestas se hubieran llevado a cabo dentro de los hogares, se cubriría otra población que relega sus actividades al espacio privado y probablemente tendría otras características ${ }^{6}$. Además, se realizaron cuatro grupos focales y cartografías sociales, con mujeres y hombres reunidos en espacios separados y diez entrevistas en profundidad, lo que ayudó a contrastar información y a profundizar en aspectos centrales.

En este artículo se presentarán los principales hallazgos y conclusiones, enfatizando en las repercusiones que las violencias de género en el espacio público tienen para las mujeres.

\section{La violencia de género, el temor y el miedo como elementos adaptativos}

En los grupos focales realizados se pudo constatar que existen diferentes percepciones de seguridad frente al espacio público entre hombres y mujeres, y que la violencia de género en este mismo espacio ha propiciado en las mujeres una estrategia adaptativa fundada en el temor y el miedo.

Los hombres con quienes se desarrolló la investigación consideraron que hay momentos y circunstancias que vuelven la ciudad más insegura y sus estrategias de defensa son diferentes a las de las mujeres; por ejemplo, no hablaron nunca de ir acompañados, sino de alargar trayectos para escoger rutas menos peligrosas, y no temen frecuentar sitios solitarios por temor a una agresión sexual, sino por ser atracados cuando caminan por lugares oscuros. Ellos sienten miedo a ser víctimas de un ataque de hinchas descontrolados cuando juega su equipo

5 Para más información ver Arias y Cardona (2012); De Miguel (2007).

6 La muestra tiene este sesgo porque no pretende ser exhaustiva ni representativa de todas las mujeres de la ciudad, sino que es un ejercicio ilustrativo que nos propusimos en la investigación. 
favorito, a sufrir un accidente en la vía pública, o a verse inmiscuidos en una riña callejera.

Es muy común cuando está jugando Nacional o Medellín, que uno llegue a asustarse hasta salir con una camiseta, aunque no sea del equipo de fútbol, digamos si está jugando Nacional salir con una camiseta roja, o sea llegar a la estación del Metro y saber que en San Antonio se van a subir o se van a bajar hinchas del Nacional, por ejemplo, y uno con una camiseta roja y tener miedo, o sea eso llega a ser muy absurdo pero pasa (F. Chaves, Grupo focal hombres, 10 de abril de 2015).

De acuerdo con Arteaga (2014), las mujeres en cambio configuran un riguroso ritual inconsciente y naturalizado para habitar el espacio público, que consiste en saber qué pueden y qué no deben hacer en los lugares de uso común. Entendemos este ritual como una práctica adaptativa después de interiorizado el miedo y la culpa y que como se verá en adelante, no es un proceso exclusivamente individual, sino reforzado por la cultura y sus principales instituciones. Ellas se ven presionadas a tener cuidado con su apariencia para no llamar la atención, a evitar lugares donde puede presentarse acoso y a no salir solas a altas horas de la noche. Este ritual evita la sospecha frente a comportamientos inadecuados que son entendidos como una transgresión al rol (List, 2007).
Una vez iba para el Centro de noche, iba sola, me monté al bus [...], entonces yo me senté al lado de la ventanilla y luego se subió un señor y se sentó al lado y desde el principio me miraba y me miraba y yo era así pues... como súper intimidada y me sentía muy acorralada porque esa silla es bien alta y el man ahí míreme y míreme y yo me hacía la loca, me volteaba, no veía la hora de llegar y entonces en algún mo- mento empezó a decirme cosas como: "Oiga usted está muy linda, ¿Usted cómo se llama? Usted no sé qué ¿Ve pa' dónde va? ¿La puedo acompañar?” [...] y en algún momento yo volteé y lo miré y tenía una mochilita o un bolsito y tenía una segueta [...] y el bus estaba muy vacío porque era de noche y de bajada casi siempre son muy vacíos; entonces yo me pegué mera empeliculada, porque el man era súper insisten- te, ya incluso como hasta grosero. Entonces me decía: "Oiga, pero míreme ¿Por qué me ignora? ¡Páreme bolas!” [...] yo me asusté un montón porque le vi esa vaina ahí y yo dije: "no, este me va a hacer algo con esto, me va a amenazar o me va a aporrear con esto". Ya iba llegando al lugar donde me tenía que bajar $[\ldots]$ yo era como ¡Jue- pucha! Ni siquiera sabía cómo pararme de ahí, porque era como ¿Qué hago? ¿Cómo le pido permiso? [...] Sí recuerdo mucho eso y de noche siempre trato de hacerme cerquita al conductor; me daba miedo encontrármelo por la casa luego, porque se montó cerca a donde yo vivo (L. López, Grupo focal mujeres, 5 de abril de 2015).

Lina López no sentía miedo de que le robaran, a diferencia de los hombres de los grupos focales, sino de que el hombre que iba en el bus intentara algún tipo de contacto sexual con ella. La forma predominante de protección de las mujeres es ignorar al agresor, en ocasiones funciona porque cesa el acoso, pero en otros casos lo incentiva; el hombre del relato continúa con una intimidación verbal, a partir de piropos y comentarios no pedidos. La antropóloga Soledad Niño (2000) afirma que el miedo es muy expresivo y comunicativo; se puede leer en el cuerpo cuando las personas modifican sus gestos y comportamientos, enviando señales claras a otros sobre la sensación de amenaza. Por ello es sorprendente la omisión de quienes observan, así como la presunción del agresor 
de que su acto no tiene afectaciones visibles en la mujer o de que como algunos plantean, es una forma de halago o cortejo. Al contrario, consideramos que ese miedo es motivante para el agresor, quien lo reconoce y se aprovecha de él para manipular o continuar la agresión. Hay una especie de autoafirmación o ratificación del poder de quien agrede, cuando el miedo es expresado.

El sentimiento de inseguridad de las mujeres en los espacios que consideran peligrosos, también se encuentra asociado a la dificultad (o constreñimiento) para asumir riesgos, ya que ellas han sido educadas para evitarlos (Román, 2009). "La inseguridad cambia el cotidiano de las personas, es un límite a la libertad, a los derechos; es en las ciudades donde cada vez más el espacio público es percibido como atemorizante" (Falú, 2009, p. 25). En este sentido, la contraposición a este estado, es decir la seguridad, podría ser una estrategia a desarrollar, apropiar y enseñar entre las mujeres porque es sinónimo de control sobre sí y de autonomía; las mujeres que corren riesgos sienten y a su vez crean mayor confianza, y en este caso el riesgo está incluso dado en la posibilidad de contestar al agresor o confrontarlo, de habitar la ciudad a la hora deseada y en la compañía deseada, en lugar de recurrir al acostumbrado silencio, indiferencia o privación de movilidad.

\begin{abstract}
A mí también me pasó algo en un bus, pero yo no quedé tan traumatizada porque sí pude reaccionar. Yo iba en un bus y a mí en los buses siempre me ha gustado hacerme en la ventana y yo monto en bus desde muy chiquita [...] creo que ya tenía por ahí unos 15, no era tan chiquita ya [...] y se me sentó un señor al lado, pero era joven [...]. Ya íbamos como 20 minutos en el bus, y hubo un momento en que me cogió la entrepierna, entonces yo lo miré inmediatamente y yo pues... reaccioné y como que me defendí, me paré y lo boletié. Pero a mí no me parece positivo que haya pasado, pero me parece que eso también me incentivó a reaccionar y a ver todas esas violencias que pasaban en la calle, por ejemplo, que en los buses es común [...] (Y. Robles, Grupo focal mujeres, 5 de abril de 2015).
\end{abstract}

A pesar de la falta de seguridad para las mujeres en los espacios urbanos, es importante resaltar que ellas siguen habitando el espacio público, aunque lo hagan con miedo; por lo tanto, crean mecanismos de defensa y de prevención contra las violencias, en unos casos defensivos (como ignorar al agresor, bajar la mirada, vestirse con recato) u ofensivos (tomar cursos de defensa personal, tener objetos para contrarrestar la agresión como gas pimienta, gritar, reaccionar, insultar o golpear). Se requiere un proceso de desaprendizaje del miedo, permitiendo que finalmente podamos ser habitantes de la ciudad, es decir, que podamos recorrerla, usarla, disfrutarla y ejercer como ciudadanas (Niño, 2000). Las soluciones planteadas en el grupo de mujeres están muy ligadas con el fortalecimiento de esa seguridad a partir de la apropiación de los espacios, de la reacción de rechazo ante las agresiones, de la desnaturalización de las violencias, de la eliminación de la culpabilización y de la organización. Todas estas herramientas apelan a la solidaridad como elemento indispensable de la cultura para fomentar la confianza y crear lazos de empatía con las situaciones que nos afectan.

Empezar a dejar el miedo y esto también aplica para el espacio público, empezar a boletear al acosador, empezar a decirle a la señora que va al lado "vea es que ese me está acosando, me lleva siguiendo una cuadra". Dejar de culpabilizarnos, la culpa 
no es de la ropa, la culpa no es de lo que te pones o como mires al tipo, es que él no tiene ningún derecho a acosarte. Yo creería que ese es uno de los primeros pasos, empezar a tomarnos las calles y hacer de esos espacios nuestros también (Delgado, citada por Toro (2015)).

\section{Cartografías del miedo con perspectiva de género}

Karsten y Meertens (1991-1992) afirman que "el espacio desborda [...] su marco geográfico y se convierte en un concepto que remite a las nociones de autonomía e identidad, y también a las prácticas sociales concomitantes en que problemas individuales son llevados al plano colectivo y público y, por lo tanto, al de la responsabilidad civil" (p. 188). De esta manera, la geografía feminista se interesa por incluir el enfoque de género dentro de la geografía y ubica la pregunta sobre la relación mujer y lugar, indagando por cómo perciben, crean o se interesan por los lugares (Monk y Hanson, 1989). Esta perspectiva insta a investigar de manera diferenciada para hombres y mujeres por la seguridad en la ciudad, a partir de su arquitectura, sus equipamientos y servicios (Karsten y Meertens, 1991-1992); (Páramo y Burbano, 2011) y (Monk y Hanson, 1989).

Identificar los tránsitos de las mujeres y los espacios en los que sienten temor o comodidad, en este caso, fue posible gracias a la aplicación de cartografías sociales diferenciadas por género. Los lugares más frecuentados por las mujeres encuestadas se agruparon por comunas (figura 1), donde aparecen todas excepto la 1 (Popular), la 2 (Santa Cruz) y la 13 (San Javier). Cada lugar fue calificado de 1 a 5 de acuerdo con el nivel de seguridad percibido, siendo 1 el más bajo y 5 el más alto.

Figura 1. Medellín por comunas

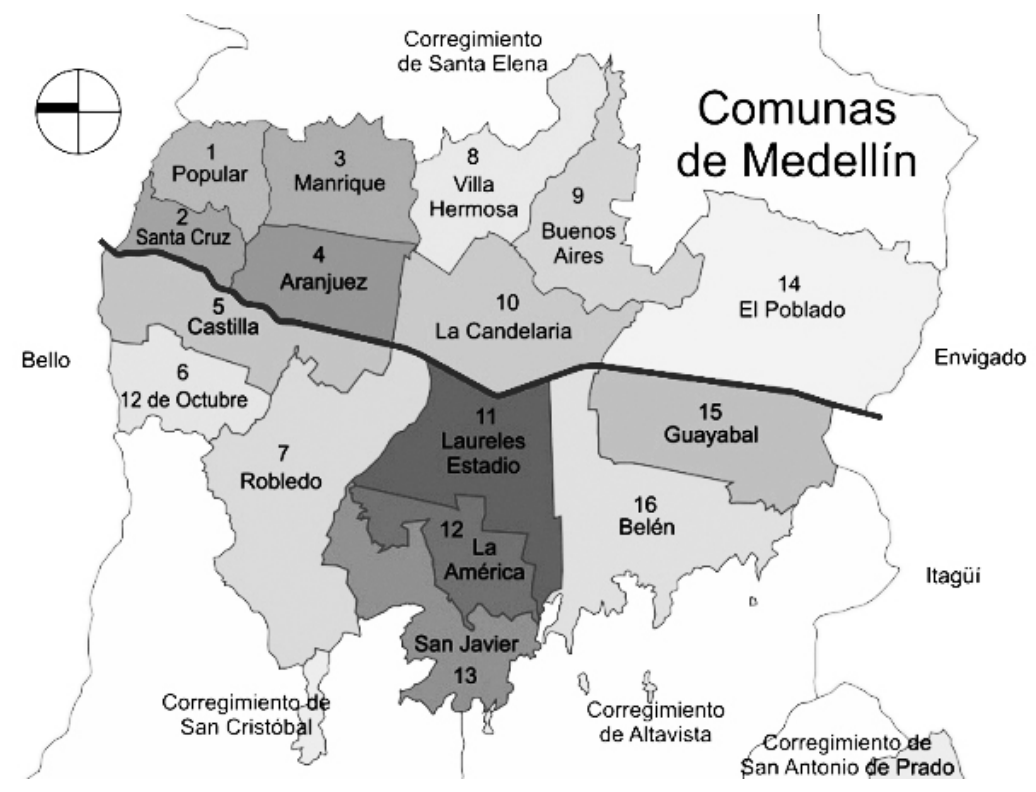

Fuente: Medellín te espera (Medellín te espera, 2015). 
El nivel de seguridad más bajo fue para la comuna 5 (Castilla), con una calificación de 2, sin embargo solo tres personas afirmaron frecuentar este sector. La Comuna más frecuentada fue la comuna 10 (Centro); 32 personas afirmaron visitar este sector constantemente, aunque es percibido como peligroso, con una calificación de 2,6. Los lugares considerados como peligrosos en la ciudad están agrupados en su mayoría en esta comuna (46 personas mencionaron sectores del Centro): Prado, Parque Bolívar, Parque Berrío, Parque San Antonio, Cisneros, Estación Prado, Avenida Oriental, sector de la Minorista, Plaza de Botero, el Hueco, Barrio Triste, Los Puentes, La Playa, sector del Teatro Pablo Tobón Uribe, Villanueva, Palacé, la Veracruz y Carabobo. A pesar de la alta percepción de inseguridad que hay en el Centro, es un lugar muy frecuentado porque confluyen en él oficinas, centros de trabajo, centros de salud, centros administrativos, instituciones, etc. La comuna 4 (Aranjuez) es la segunda más concurrida, con una percepción de seguridad de 3,8 y se mencionaron cuatro lugares de ella como peligrosos: sector de la Universidad de Antioquia, detrás del Jardín Botánico, Estación Hospital y Moravia. Dentro de las más frecuentadas también está la comuna 7 (Robledo), calificada con 3,8 en la que los lugares encontrados como peligrosos son: el Cerro el Volador, La Iguaná, sector de la fábrica de Coca-Cola, Punto Cero y la Carrera 65. La comuna 11 (Laureles-Estadio) y la comuna 14 (Poblado), donde se encuentran en su mayoría barrios estratificados en 4, 5 y 6 tienen una percepción de seguridad alta (4).

Otros lugares mencionados como peligrosos son San Diego, Santo Domingo, Lovaina, Belencito Corazón, Belén Los Alpes, Manrique, Belén Altavista, El Picacho, San Javier, estación del Metro Industriales y Barrio Antioquia. También hay asociación de peligro con "barrios de invasión" y "barrios populares" como respuesta a los imaginarios de violencia y de inseguridad que se han creado en torno a estos lugares. Otras mujeres consideran la calle como peligrosa, sin indicar ningún lugar específico: "estar en la calle es peligroso", "en cualquier lugar te puede pasar algo", "todos los lugares son peligrosos, depende del horario y si son muy solos" (Mujeres encuestadas, comunicación personal J. Toro, 27 de Febrero de 2015).

Esto en cuanto a lugares que se consideran peligrosos en general, que abarcan un amplio espectro de la ciudad y dan la impresión de Medellín como un lugar peligroso en el que los espacios más seguros se asocian a barrios donde vive la gente de clase alta. Hubo a su vez otro grupo de preguntas que hacían referencia a lugares peligrosos específicamente para las mujeres (en razón del género): vuelve a aparecer la comuna 10 (con 33 respuestas) y la comuna 7 (con 7 respuestas). Adicionalmente, en esta pregunta se presenta una nueva categoría que es "todos [los lugares]", con una frecuencia de 12 respuestas, lo que significa que varias de las mujeres encuestadas no se sienten seguras en ningún lugar de la ciudad.

La percepción de inseguridad está por un lado asociada a un lugar específico, y por otro, a una sensación de miedo generalizada. Para Román (2009), el miedo es inoculado con mensajes inocentes desde la infancia y opera como una "caja de resonancia del discurso ancestral" cada vez que se establece la idea de que la mujer que está en la calle, está fuera de lugar. De Miguel (2007) cita a la autora Sussan Brownmiller, quien asegura que todas las mujeres son víctimas 
de violación aunque no la hayan sufrido, porque el temor a que ocurra condiciona su comportamiento cotidiano y propicia actitudes preventivas sistemáticas. "Las mujeres que nunca han sido violadas muestran una ansiedad y unos miedos similares a las que sí lo han sido" (p. 78), y con el fin de evitar que les pase, limitan su autonomía en el espacio público. Hay un mensaje que subyace a las restricciones que asumen las mujeres con respecto al uso de los espacios: es posible que una mujer realice tranquilamente todas las actividades siempre y cuando esté acompañada de un varón, porque con una mujer también se va a sentir vulnerable. Según este análisis "el mensaje de la violencia o la violencia latente contra las mujeres está muy claro: una mujer «sola» está en peligro" (De Miguel, 2007, p. 78).

Para indagar lo anterior y como parte de la encuesta realizada se preguntó por los lugares concurridos, los seguros e inseguros, información que se contrastó en los grupos focales con hombres y mujeres, para obtener así una perspectiva del uso diferencial de los espacios públicos. De 54 lugares mencionados como seguros para las mujeres, solo diez se caracterizan por ser abiertos, prevaleciendo zonas residenciales de clase media o alta: El Estadio, Pilarica, Calasanz, Los Colores, Laureles, Robledo, Belén; y lugares culturales o recreativos al aire libre como el Parque de los Deseos, Ciudad del Río, La Villa de Aburrá y el Parque Pies Descalzos. También se señalaron sectores de esparcimiento como Oviedo (centro comercial) y el Poblado (barrio de clase alta). Esta asociación de lugares seguros con características como la belleza, limpieza, el orden y un estrato económico relativamente alto, contrasta con la percepción de inseguridad igual a pobreza, desorden y suciedad?

La ciudad construida en el imaginario social como "buena" es esa físicamente hermosa, bien cuidada, con una infraestructura adecuada a las necesidades del mercado, limpia, en contraste con la ciudad "mala", que contiene a los sectores populares, las zonas de las plazas de mercado y de vicio, y los lugares de esparcimiento nocturno como bares y discotecas (Reguillo, 1998). En este caso coinciden dos elementos importantes: por un lado, las valoraciones de lo bueno y lo deseable y por otro, que efectivamente es en estos lugares donde se robustece la seguridad privada, en la que la gente de la ciudad deposita mayor confianza que en la pública, por su aparente efectividad.

En el grupo focal de los hombres prevalecieron como seguros los sitios abiertos pero coinciden con las mujeres en identificar como seguras zonas residenciales de estratos medios o altos: Calasanz, La Floresta, Los Colores, el sector de la Cuarta Brigada, Robledo, El Poblado. A diferencia de las mujeres, los hombres mencionaron como seguros sectores de esparcimiento reconocidos como zonas de tolerancia: al frente de la Universidad de Antioquia (la curva) y la plazoleta del barrio Carlos E. Restrepo. Estas percepciones de seguridad frente a los lugares se encuentran relacionadas con la diferenciación que hay en la configuración del espacio urbano entre hombres y mujeres, y de su habitabilidad; en ese

7 En este mismo sentido los pobres son asociados con la inutilidad, la ignorancia y la flojera y se les reconoce en la ciudad por acciones como pedir, chantajear, delinquir y mentir; se piensan como operadores de las violencias urbanas y, así como la arquitectura de la pobreza, ellos son percibidos como sucios y feos (Reguillo, 2000). 
sentido los hombres están más apropiados del espacio público y abierto y de lugares donde se convive con lo liminal como las zonas de tolerancia.

Las mujeres sienten un temor particular por lugares como canalizaciones, franjas boscosas y callejones, porque son solitarios y carecen de iluminación y vigilancia. En las encuestas realizadas ante la pregunta ¿Cuáles lugares considera seguros para las mujeres? Se encontraron las siguientes opiniones: "aquellos lugares muy frecuentados", "los lugares donde haya seguridad o que haya flujo de gente y que sea de día", "lugares públicos con vigilancia", "lugares concurridos", "lugares donde no esté sola", "las calles y lugares más cercanos a mi casa", "lugares con muchas personas" (Mujeres encuestadas, comunicación personal J. Toro, 27 de Febrero de 2015).

La lógica de género que opera en la ciudad impone límites y fronteras que se vuelven naturales; pocas veces las mujeres son conscientes de la exclusión de la que hacen parte, simplemente la viven. Para las mujeres encuestadas (23), son más seguros los lugares cerrados mencionando centros comerciales, universidades, centros culturales, parques de diversiones, bibliotecas, museos y oficinas, caracterizados por contar con vigilancia y ser bastante concurridos: "En general considero seguros lugares cerrados y bajo vigilancia", "algún lugar afuera no es seguro", "la universidad en el día" (Mujeres encuestadas, 2015). ${ }^{8}$ También se nombran las casas de amigos o familiares, que aunque no cuentan con vigilancia, son habitados por personas cercanas frente a las que no sienten amenaza. Hay otras mujeres que solo creen estar seguras en sus casas (1l) y otras más que piensan que ningún lugar es seguro para ellas por su condición de género (10). Estas últimas son las más jóvenes (entre los 16 y 25 años), las de clase media (de 7 mujeres encuestadas con vivienda en estrato 4, 5 coincidieron en que no hay ningún lugar seguro) y las que tienen algún tipo de educación superior (6 profesionales de las 17 encuestadas). Esto puede deberse a que tienen mayor acceso a la información y que están al tanto de la violencia de género, lo que las alerta frente a ella.

En los grupos focales, la mayoría de lugares localizados por las mujeres como potencialmente peligrosos están asociados con situaciones de acoso sexual callejero 9 que experimentan cotidianamente. Aunque las mujeres también expresaron sentir temor a ser atracadas, esta es una preocupación menor; sigue presente la idea de que es mejor ser víctima de un robo que de una agresión sexual (figura 2).

Hay lugares que me dan miedo de noche por robo, pero como que el principal miedo es ese miedo a que por mi condición de mujer, como que me toquen, me violen [...] Por la Estación Hospital me robaron una vez [...] y claro lo primero que me preguntaron cuando conté es: 'venga ¿y no le hicieron más nada, no la tocaron, no la violaron?' [...] uno dice: jjuepucha! menos mal solo me quitaron las cosas, menos mal no me tocaron ni me hicieron más nada (L. López, Grupo focal mujeres, 2 de abril de 2015).

8 Sin embargo, esto no deja de ser paradójico puesto que muchas de las agresiones a las mujeres se dan por familiares o amigos y dentro de sus casas. Este asunto, será objeto de otra indagación y por eso no se elabora aquí.

9 Los lugares referenciados en las cartografías elaboradas por hombres y mujeres se encuentran relacionados, casi en su totalidad, con episodios de violencia; los mapas dan cuenta entonces de los sitios más frecuentados por los participantes, aunque algunos sí señalaron zonas a las que no van constantemente pero que consideran peligrosas. 
Figura 2. Cartografía social elaborada en grupo focal de mujeres (color)

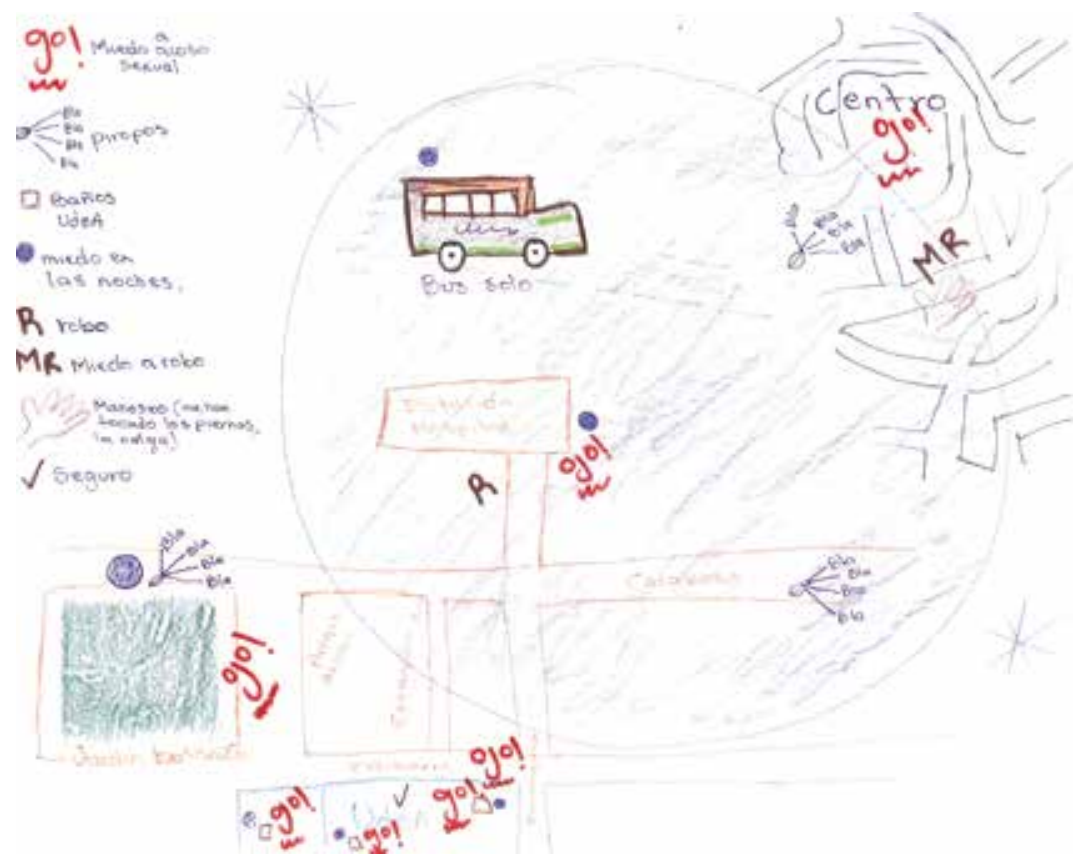

Fuente: L. López, Cartografía, Grupo focal de Mujeres, 2015.

Los lugares solitarios y la noche aumentan la percepción de peligro. El 54\% de las mujeres encuestadas cree que hay horarios en los que no debe transitar por la ciudad, frente a $46 \%$ que está en desacuerdo. Las franjas horarias señaladas como inseguras son la noche y la madrugada (después de las 6:00 pm). No obstante, la mayoría piensa que debería poder transitar a la hora que quisiera, pero no lo hace por la percepción de peligro, que aumenta cuando está sola: "Deberíamos transitar a cualquier hora", "no podemos transitar por la inseguridad", "no debe haber restricciones de transitar a la hora que queramos, siendo las mujeres que queramos ser", "la mujer se vuelve más vulnerable en la noche por la soledad", "no deben transitar sin compañía y en la noche (no debería ser así, pero estamos hablando de hechos)", "para salir en la noche deben estar acompañadas", "no «deben», se ven obligadas a no salir por las noches, pues son más vulnerables", "no me parece que la solución deba ser el dejar de transitar ciertos lugares", "no debemos andar en la noche por lugares muy solos", "en todo momento estamos en peligro, aunque en la noche me siento más insegura", "creo que no debería ser así pero la noche es más peligrosa para nosotras" (Mujeres Encuestadas, 2015).

En los grupos focales y por medio de observación participante se identificaron espacios masculinizados o con mayor presencia de hombres, como los parques donde se hace ejercicio, las canchas de los barrios, las plazas de vicio, los acopios de taxis, las zonas de parqueaderos y talleres, los sectores donde hay ferreterías, las esquinas. Las mujeres afirmaron que cuando pasan por estos lugares son objeto de comentarios sexuales y coincidieron en que cuando van a 
pasar por ahí ya están preparadas para que les digan cosas desagradables o incómodas y asumen formas de protección como pasarse de acera, taparse el escote de la camisa, bajarse la falda y bajar la mirada.

"Si uno sabe que va a esos lugares no se pone cierto tipo de ropa" (M. Delgado, Grupo focal mujeres, 5 de abril de 2015).

"Yo sí creo que hay lugares donde no iría sola a altas horas de la noche, al Parque Berrío, a las partes del Centro más abajo, digamos que por la Iguaná arriba tampoco iría sola" (Y. Robles, Grupo focal mujeres, 5 de abril de 2015).

"No, y bajarme de noche sola por esa montaña, yo no me lo imagino, porque se puede prestar para que lo metan a un matorral a uno y lo violen y pues yo creo que nadie se daría cuenta" (L. López, Grupo focal mujeres, 5 de abril de 2015).

Los hombres no experimentan ese peligro y tampoco consideran que a las mujeres les pueda pasar algo en lugares donde hay fuerte presencia de hombres, es decir, perciben como una exageración el temor de las mujeres. Los espacios masculinizados encontrados son: en el Centro la calle Echeverri entre carrera 43 y carrera 49; Carabobo (por la zona de talleres); la calle Barranquilla por la Universidad de Antioquia; detrás del Jardín Botánico; alrededores de la Estación Hospital; la carrera Bolívar, llegando a la calle San Juan; y aledaños a la Estación Prado, por el viaducto del Metro.

Por su parte, los hombres catalogaron como inseguros lugares donde reconocen la existencia de fronteras invisibles, ${ }^{10} \mathrm{y}$ enunciaron barrios que son controlados por grupos armados.

En Medellín en muchos sectores donde he estado, donde hay plazas de vicio, o donde todavía son puntos estratégicos de la ciudad, hay una tensión por la disputa de territorios y se han establecido desde hace mucho tiempo los paramilitares en la ciudad, entonces digamos que ese es otro miedo con el que hay que lidiar (C. Portilla, Grupo focal hombres, 15 de abril de 2015).

Los lugares mencionados son: Guayabal, la Aguacatala, Boston, Villa Hermosa, Jardín Botánico, El Pomar, Campo Valdés, Manrique, Caribe, Santo Domingo, Popular, Picacho, Doce de Octubre, Pedregal, Boyacá, San Javier, cerca de Coca-Cola por la Universidad de Antioquia, un sector en Castilla, el Centro, sector de Punto Cero y Avenida Regional. Pero en general, los hombres transitan seguros por el espacio público, porque no temen sufrir acoso sexual, pues como ellos lo reconocieron son las mujeres quienes están más expuestas a esto (figura 3).

10 Este temor a las fronteras invisibles se encuentra asociado a la construcción de masculinidades, que relacionan al hombre con la territorialidad y su defensa y con el uso de la violencia y de las armas. Los hombres desde pequeños configuran formas de conducta relacionadas con la demostración de poder, que se da por medio de la fuerza y de la violencia; esta lógica va de la mano con la participación de los hombres en la guerra y su vinculación a grupos armados, de manera voluntaria o a través del reclutamiento forzado, por lo cual ellos están más vinculados al conflicto armado y protagonizan en mayor medida formas de violencia (Faur, 2004). En este sentido, los hombres temen ser víctimas de la violencia de los barrios o ser reclutados para la guerra. 
Figura 3. Cartografía social elaborada en grupo focal de hombres
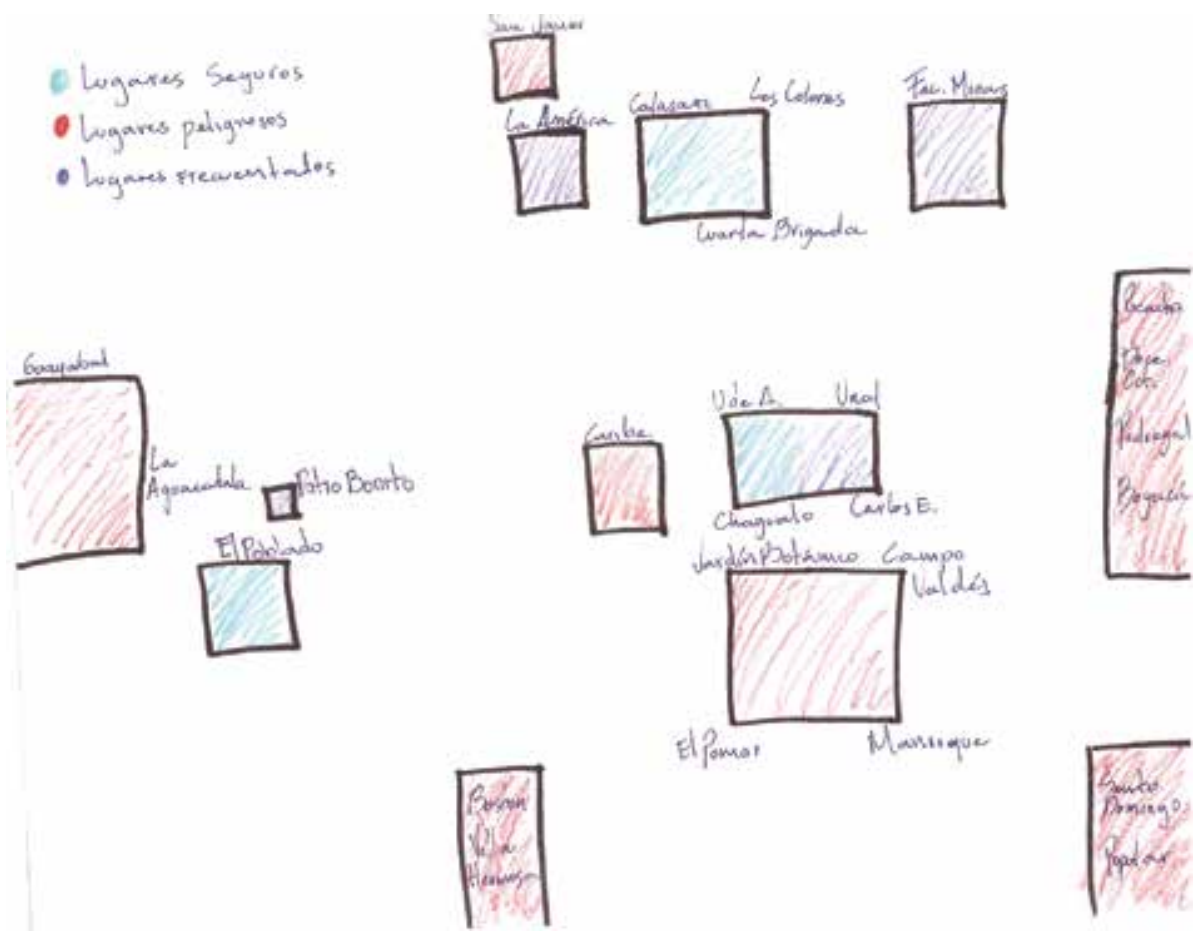

Fuente: Portilla, Cartografía, Grupo focal hombres, 2015.

\section{El acoso sexual en el espacio público}

Yo venía en el bus, eso fue en un bus de la Milagrosa, venía para el trabajo y el bus venía muy lleno; entonces, cuando me iba a bajar del bus tenía el pantalón así chorríao horrible y entonces una señora se puso como a gozarme, dizque: "ay, vea le tiraron gargajo" y yo: "ay, como asî", "ay ¿qué es eso?", entonces yo le dije: "pero, ay, el que me echó ese gargajo sí tenía pues mucha gripa" y me dice: "no, eso no es gargajo, ¿usted no sabe qué es?" Y yo: "no ¿qué es eso?” Entonces ya la señora me explicó que alguien venía detrás de mí y se había desarrollado ahí. Entonces, pues, yo me quedé como aterrada, porque en esa época uno era muy inocente y a uno no le explicaban nada. Tantas cosas así... entonces pues eso me dejó como pensando mucho: ¿Cómo así que un hombre es capaz de hacer eso en un bus? Entonces a mí ya sí me daba como sustico montarme a un bus cuando estaba muy lleno, o sea yo más bien esperaba. Entonces, fue una de las cosas que me pasó, que me preocupaba mucho y me dejó como un poquito traumatizada (G. Jiménez, Grupo focal mujeres, 2 de abril de 2015).

Hombres y mujeres reconocen como violencia los tocamientos, manoseos y masturbación, por ello los agresores los ejecutan en el anonimato; aprovechan los tumultos (esto es muy frecuente en el transporte público) y los lugares solitarios o que cuentan con poca iluminación. 


\begin{abstract}
Para ir a la universidad me tocaba pasar un puente peatonal y un día yo iba para clase en la mañana y todo estaba solo; yo iba subiendo e iba bajando un señor muy grande, más grande que yo y el señor, cuando nos cruzamos... yo iba subiendo las escaleras, cuando nos cruzamos él me lanzó su mano a los senos, entonces yo en ese momento no supe bien qué hacer, me quedé paralizada como por dos segundos, pero luego le empujé la mano. Él lo que me respondió muy descaradamente fue algo como: "pero si yo puedo"; yo no le presté atención, sino que lo que quería era irme, seguí caminando, entonces él como pa demostrarme que podía me pegó con la mano en las nalgas... de todos modos no le dije nada, sino que seguí caminando. Ese día yo tenía una blusa escotada, le conté a mis amigos y mis amigos me dijeron: "no pues ya no te pongas más esa blusa", cosas así, como si fuera culpa mía... incluso dejé de ponerme la blusa (Anillo, citado por Toro (2015)).
\end{abstract}

En general, las mujeres no saben cómo reaccionar ante el acoso, por más violento que sea; lo "usual" es ignorar los hechos, aunque causen rabia, frustración, impotencia o asco (Lainez, 2013); esa evasión está atravesada por el desconcierto y la sumisión. Alrededor de estas sensaciones se va construyendo un ambiente de aceptación hacia las violencias de género y de culpabilización de las víctimas, se tiene la percepción de que estas agresiones son provocadas por la forma de vestir, de caminar, de maquillarse o de hablar de determinadas mujeres. No importa si la agresión incluye tocamientos y roces con alguna parte del cuerpo (esto se da especialmente en los senos y los glúteos), estos actos se justifican en que la mujer agredida se presentaba demasiado seductora (Arteaga, 2014).

Las violencias contra las mujeres en los espacios públicos se legitiman, es decir, son aceptadas socialmente, incluso por algunas mujeres; hay una naturalización de esas violencias, relacionada en parte con la cotidianidad de los hechos y con la posición que se asigna a las mujeres en la sociedad. "Esta legitimación procede de la conceptualización de las mujeres como inferiores y como propiedades de los varones, a los que deben respeto y obediencia" (De Miguel, 2007, p. 74).

Yo soy de Valledupar. He vivido como en una zona de talleres y siempre que uno
pasaba por ahí para ir al colegio, por la tarde sobre todo, o a las bibliotecas de Va-
lledupar, le decían muchas cosas a uno y yo, yo siempre me defendía, como que les
decía que me respetaran y a veces cuando ellos me respondían después de que yo
les decía que me respetaran y por ahí había una piedra yo la cogía y les decía: "no te
acerques más porque te voy a tirar esta piedra", y un día yo iba con una amiga y a las
dos empezaron a molestarnos y yo hice lo mismo y mi amiga me dijo que bajara esa
piedra, que parecía una loca y yo recuerdo que desde ahí -y eso fue como entre los
11 y los 15 , no sé qué edad tendría pero fue en ese rango de tiempo- y yo me acuer-
do que desde ahí, cada vez como que me dicen algo lo pienso dos veces para respon-
der, como que eso sí me marcó (T. Anillo, Grupo focal mujeres, 2 de abril de 2015).

La aceptación y naturalización de la violencia de género tiene como correlato la incapacidad de respuesta de las mujeres ante las agresiones, incluso cuando logran hacerlo se pueden sentir extrañas e inseguras, fuera de su rol, diferentes al resto del grupo.

Hace días yo no sé pa' dónde íbamos, salí con mi familia; y el man que iba manejando el taxi era como amigo del compañero de mi hermana; y eran recochando ahí, 
y el man pues pasaba y les gritaba cosas a todas las mujeres y los de mi casa eran cagados de la risa, y tocaba nalga, y yo era como que no sabía... Pues, porque es muy teso, pues yo creo que me miraban y sabían que me incomodaba, pero como que llegar ahí..., pues no sé, me dio muchísima rabia. Es muy complejo, como que uno no sabe cómo llegar y plantear esas cosas [inconformidades ante el acoso] [...] es muy peye, yo me sentía mal, como "juepucha por qué no dije", como que si es justo plantearlo por qué no lo dije, como ¡qué mierda! (L. López, Grupo focal mujeres, 2 de abril de 2015).

Las mujeres lidian con el acoso y generalmente lo hacen solas; pocas personas están dispuestas a intervenir cuando presencian una agresión, porque por un lado, este tipo de actos se han normalizado dentro de la sociedad y se ven como asuntos de la vida privada de las mujeres, y por otro, hay un temor a recibir una mala respuesta por parte de los agresores o de las víctimas o de que el acoso se convierta en violación.

Yo iba por el Centro y realmente era temprano, no eran más de las 5 de la tarde yo creo, iba con una amiga y un man estaba teniendo una discusión muy acalorada con una mujer, incluso la estaba maltratando, pues la tenía de los hombros, la estaba sacudiendo, nunca vimos que la golpeara, pero la estaba sacudiendo y las dos reaccionamos y fuimos y le dijimos: "ey ¿qué le pasa? ¿cómo la está maltratando?” y el man se volteó y nos dijo: "Ah, hijueputas ¿qué les pasa? esto no es problema suyo, ¡vénganse!”; incluso se arrimó a mi amiga que estaba más cerca de ellos y entonces yo fui a separarlos, porque como que él ya iba a golpear a la mujer y la mujer terminó golpeándome, quitándome y dijo: "ay, qué les pasa, esto no es problema de ustedes, no se metan, esto lo arreglo entre el man y yo". Entonces pasaron dos manes, como que también iban a separarlos y nos dijeron a nosotras: "no, sí, vengan, no nos metamos"... y como que nosotras no caímos en cuenta de la situación y dijimos: "bueno, sí que lo arreglen ellos". Ellos se fueron, el man la siguió gritando, se fueron lejos, pero al final nosotras íbamos como que: "ah sí pero ¿por qué nos metimos? ¡muchas sapas!”... a veces uno es consciente de que las cosas están mal y tiene que actuar para eso, pero las reacciones de las otras personas hacen que uno llegue incluso a dudar de ese acto que uno sabe que está bien (Y. Robles, Grupo focal mujeres, 2 de abril de 2015).

Iba en una calle por aquí por el Centro, de las calles concurridas que hay en el Hueco, iba caminando [...] un man me empieza a piropear, la primera medida que generalmente uno toma es no prestarle atención, yo seguí caminando y el man siguió piropeando, siguió, tanto así que fue una situación pesada, porque fue casi una cuadra y el man detrás y no pasaba nada y yo lo único que opté por hacer fue seguir caminando, así me sintiera incómoda; incómoda y también atemorizada, porque ¿Este man qué? ¿Por qué me persigue una cuadra diciéndome cosas? y no pasaba absolutamente nada era solo conmigo: "Ella verá, ¿quién sabe por qué le está diciendo eso?" Algo así fue lo que sentí en todo ese momento, porque también sentí que la gente lo vio, que muchas personas lo vieron, hombres, mujeres, y no pasó nada, está naturalizado, es ella allá (Delgado, citado por Toro (2015)).

Hay pues dos situaciones expresadas en los testimonios: quienes intervienen, pese a ser desconocidos, son alejados por "meterse en un asunto doméstico, privado", y quienes no lo hacen tal vez prevenidos por situaciones de esta índole, lo que genera una sensación de soledad en las mujeres que sí quieren protección, y que no perciben acciones de solidaridad de quienes son testigos del acoso; en este sentido, 
su miedo persiste aunque se encuentren en lugares en los que transita un gran número de personas. En torno a estas acciones de indiferencia, inseguridad, falta de respuesta y miedo, el acoso callejero continúa reproduciéndose y reafirmándose como una conducta masculina socialmente aceptada y legitimada (incluso en algunos casos por la víctima, como se ve en el relato), que sostiene una estructura de género desigual, en la que los hombres poseen privilegios sobre las mujeres. Este orden establecido se mantiene y se reafirma, además, con actos de violencia más crueles y visibles como formas de "castigo ejemplarizante" para las mujeres que trastocan el rol.

Cuando yo me vine para Medellín a estudiar, empecé en el Sena, ya después me resultó un puesto en la Universidad de Medellín y empecé a estudiar el primer semestre y llevaba por ahí tres meses más o menos, cuando una vez que llegué a mi casa (yo vivía cuando eso en la Milagrosa) encontré un volante debajo de la puerta que decía que las mujeres no se debían vestir muy destapadas y que no debían salir hasta altas horas de la noche. Entonces la verdad yo no le presté mucha atención a eso porque yo siempre usaba ropa muy cubierta y fuera de eso no salía hasta tarde porque me daba miedo... Pero una vez que iba para la casa, iba llegando ya a la casa, me abordaron dos personas que me dijeron que si era que yo no había entendido lo que me habían dejado; entonces yo, pues me asusté mucho, porque de verdad que yo no creí que eso era para mí. Mi papá me había dicho que no estudiara en la universidad, porque el horario era por la noche, era de 6 a 9 de la noche, y a él le daba mucho miedo, que porque acá en Medellín era muy peligroso y que a las muchachas las violaban, que las atracaban... una cantidad de cosas; entonces a partir de ese momento yo decidí no continuar estudiando en la universidad. A mí lo que más me afectó realmente fue la salida de la universidad porque yo quería ser abogada (Jiménez, citada por Toro (2015)).

Gilma Jiménez, protagonista del documental Mujeres, a la calle (Toro, 2015), cuenta en el documental cómo sufrió agresiones reiteradas perpetradas por hombres y relacionadas con su condición de mujer. Ante amenazas de actores armados del barrio, y frente a su prohibición de circular en la noche como aparece en este episodio, tuvo que dejar el estudio; su proyecto de vida fue violentamente interrumpido y refleja la situación de pérdida de autonomía de algunas mujeres que habitan lugares en los que el control lo ejercen actores ilegales.

\section{Conclusiones}

Medellín ha sido ejemplo de transformación urbana, presentando cambios notorios en su infraestructura y en la recuperación del espacio público, ha ganado premios internacionales y ha sido reconocida como una ciudad innovadora en relación con las transformaciones urbanísticas. No obstante, la perspectiva de género no ha sido transversal a la planificación urbana, los espacios públicos continúan siendo heteronormativos y no se preguntan por las necesidades diferenciadas de hombres y mujeres; son ajenos a la población LGBTI (lesbianas, gays, bisexuales, transgénero, intersexuados) que se relega a zonas diferenciadas de la ciudad, lo que evidencia patrones excluyentes de relacionamiento. En muchas ciudades se sigue este mismo esquema: la ideología masculina es evidente en la planificación urbana, el diseño espacial se centra en las actividades laborales "masculinas", lo que dificulta los desplazamientos de las mujeres y 
establece guetos para diferentes grupos sociales que segmentan el espacio público siguiendo jerarquías culturales" ${ }^{11}$.

En este sentido, la conclusión más determinante de este estudio es que en Medellín persisten los problemas de exclusión, desigualdad y violencia de género y son reflejados en la forma de habitar el espacio público: las mujeres evitan ciertos trayectos y disponen un ritual corporal restrictivo por temor a situaciones de violencia asociadas a su condición de género, especialmente por el temor a la violación. El aspecto más señalado por diversas investigaciones en el campo de la geografía feminista en la relación género y espacio es la restricción a la libre movilidad de las mujeres, quienes limitan sus tránsitos a lugares cerrados, iluminados y vigilados y evitan aquellos oscuros, solos o valorados como masculinos. A ello se suma que conductas experimentadas por las mujeres como los piropos o el acoso callejero, por su carácter diario (en el caso de los piropos y las miradas con connotaciones sexuales), sistemático, no consentido y emitido por extraños y desconocidos de quienes no se puede prever reacción, fomentan la sensación de peligro y la percepción de temor a los espacios públicos y reducen su apropiación.

La división de los sexos reproducida en las prácticas diarias se vuelve parte orgánica de la vida social, estableciendo patrones de comportamiento regulares, que se perciben como espontáneos, se dan de forma mecánica y no reflexionada. Tácitamente se establecen regulaciones colectivas que conforman conductas esperadas frente a la resolución de situaciones cotidianas. Las recomendaciones y distribuciones de roles siguen una tendencia a la infantilización de las mujeres (protegidas por los hombres); por lo tanto, no se indaga ni se explica por las causas de las prohibiciones y no se les enseña a defenderse, todo lo contrario, se imparten restricciones que las hace sentir vulnerables.

Los marcados imaginarios de temor que tienen las mujeres frente a ciertos espacios, lugares o situaciones son vistos por los hombres como irracionales e incluso no siempre son expresados conscientemente por las mujeres, sin tener en cuenta que la seguridad e inseguridad están relacionadas con condiciones objetivas, pero también con representaciones frente a lugares y las posibles consecuencias de habitarlos. El miedo es aprendido y por lo tanto cultural: los objetos, lugares o personas del miedo tienen que ver con la posición del individuo dentro de la sociedad. Así que el temor puede existir y dispararse frente a situaciones menores que pongan en alerta al sujeto (en este caso las mujeres) y no solamente por haber vivido una experiencia traumática, sino también por la amenaza de vivirla. Vivir con miedo tiene consecuencias en la forma de pensar, de habitar y de usar la ciudad. Las mujeres dudan para denunciar, temen pedir ayuda y no quieren defenderse por temor a una nueva agresión; o quienes no han apropiado el discurso de género defienden al agresor y evitan intervenciones externas (especialmente cuando este es un conocido o su pareja).

Il Aunque las mujeres han ingresado al mercado laboral y hay mayor reconocimiento de sus derechos, la distribución de las responsabilidades domésticas no muestra transformaciones significativas: ellas continúan siendo las principales encargadas de las tareas del hogar; de lo que puede inferirse que el uso del espacio público con fines de entretenimiento es mayor para hombres que para mujeres. Todo esto con diferencias de acuerdo con la clase social, pues a menor capacidad adquisitiva menor disponibilidad de tiempo como recurso propio. 
No se puede desconocer que esos temores se encuentran justificados en los diferentes abusos que sufren las mujeres, que van desde una mirada persistente y morbosa hasta la violación y el feminicidio. Desde la adolescencia, las mujeres conviven diariamente con las miradas, el escrutinio y los comentarios soeces sobre su cuerpo, sufren acoso sexual callejero de manera cotidiana, y todas las mujeres han vivido al menos una situación que las ha perturbado por su condición de mujer. Esto genera incomodidad e inseguridad, reafirmando la necesidad de las medidas de protección dadas en casa, lo que refuerza el estereotipo y lo vuelve cíclico: no transitar por determinados lugares, no usar cierto tipo de ropa, o salir acompañadas (por un hombre).

En esta cultura y por medio de las instituciones de socialización primaria, se asume y se transmite la idea de que los hombres son incapaces de controlarse, tienen que ser activos sexualmente y arriesgados moralmente, por tanto deben ser ellas quienes ponen los límites. Esto se evidencia en frases populares como "el hombre propone y la mujer dispone", "una mujer debe darse su lugar", "no hay que dar papaya", "papaya puesta papaya partida" o "no se les puede dar mucha confianza a los hombres porque se aprovechan"; bajo esta estructura de razonamiento, la responsabilidad de la agresión recae sobre la víctima. La culpabilización de las mujeres se da en forma de señalamiento, bajo la mirada inquisidora de la sociedad y la reproducen las mujeres víctimas de las agresiones, lo que conduce a que tiendan a dudar de la falta de consentimiento, en caso de que se presente algún tipo de acoso. A las mujeres, se les educa para el autocontrol y para desarrollar estrategias de autoprotección que pueden estar asociadas a deserotizar sus cuerpos, vestimentas y actitudes, y a evitar lugares de amenaza latente.

Por otro lado, un aspecto que llama fuertemente la atención es que jurídicamente se evidencia dilatación de procesos para resolver casos de violencias contra las mujeres; algunas víctimas han tenido que esperar hasta tres años para que se dicten medidas de aseguramiento contra sus agresores y comiencen con la judicialización, a pesar de la gravedad de las violencias. Los conceptos usados para castigar a los victimarios no están en consonancia con las categorías que ha aportado el feminismo para entender este fenómeno ni con los tipos de violencia de género, lo cual le resta gravedad a los hechos. Por el momento, las mujeres han tenido que desarrollar estrategias de protección contra el acoso, donde priman las restricciones en el uso del espacio público a altas horas de la noche, las limitaciones en la forma de vestirse cuando saben que van a pasar por lugares donde hay muchos hombres reunidos y salir acompañadas o aprender algún tipo de defensa; pero es importante que como ciudadanas se apropien del derecho a la ciudad y conciban integralmente este derecho. Las luchas feministas y la introducción de la perspectiva de género en la concepción de ciudad ha permitido ver cómo los espacios públicos están enmarcados en lógicas masculinas y el problema se posiciona paulatinamente en la agenda pública, paso indispensable para un cambio.

Para que haya una modificación en este sentido, debe reforzarse sobre todo el cuestionamiento cultural, lo que implica que hombres y mujeres reconozcan las estructuras de poder en las que se insertan sus relaciones y estén dispuestos a transformarlas. Es decir, que estas situaciones sean vistas como un problema social que merece ser resuelto y puesto en la agenda pública. Tal y como sucede 
actualmente, recae sobre la mujer la agresión, la culpabilidad y la prevención; ubicar el problema en la cultura (impartida por las principales instituciones de la sociedad como la familia, la religión y la escuela) busca en última instancia que el hombre se cuestione esa idea de propiedad, uso y acceso libre, desnudo y descarnado sobre la mujer y que ella se cuestione sobre su capacidad de respuesta, su espacio íntimo y su derecho al anonimato; a que la responsabilidad se ubique en el agresor y se trastoquen los patrones que impelen a los hombres al arrojo y a las mujeres al recato; a preguntarse por qué los hombres tienden a reaccionar frente a una mujer "llevados por el instinto" que realmente es más una construcción cultural que un mandato orgánico, y a que las mujeres lo reciban sin capacidad de agencia entre el silencio y la vergüenza. Es pues indispensable fortalecer la capacidad de agencia de las mujeres, su autonomía y empoderamiento.

El primer paso es identificar y nombrar el acoso sexual contra las mujeres como un problema; de allí se pretende reducir el número de acciones violentas en el espacio público haciendo efectivas las sanciones morales al respecto y favoreciendo la reacción solidaria de quienes observan. Esto porque si bien el acoso sexual está tipificado como delito, la sanción legal no es eficaz, no es suficiente y aumenta el ciclo de violencia sin necesariamente reestructurar los sistemas de creencias. Todavía algunos sujetos carecen de la plenitud de derechos, entre ellos, las mujeres y la población LGBTI; los esfuerzos deben entonces estar encaminados a la producción de nuevos valores culturales en todas las instituciones, en los que la equidad de género sea indispensable, necesaria y todas las personas puedan acceder a los mismos derechos.

\section{Referencias}

Alta Consejería Presidencial para la Equidad de la Mujer. (2012). Lineamientos de la Política Pública Nacional de Equidad de Género para las Mujeres. Recuperado de http://www.equidadmujer.gov.co/Documents/Lineamientospolitica-publica-equidad-de-genero.pdf

Arias, G. y Cardona, L. (2012). Hacia una comprensión psicosocial de la violencia basada en el género: una mirada desde las categorías de legitimación, naturalización e ideología. Textos y Sentidos, (5), 57-82.

Arteaga, M. D. (2014). ¿A dónde tan solita? Mujeres, lugares públicos y acoso sexual callejero. Recuperado de http://alaizquierda.com.mx/2014/12/04/a-donde-tansolita-mujeres-lugares-publicos-y-acoso-sexual-callejero/

Bourdieu, P. (1998). La dominación masculina. Barcelona, España: Anagrama.

De Miguel, A. (2007). El proceso de redefinición de la violencia contra las mujeres: de drama personal a problema político. Revista de Filosofía, (42), 71-82.

Falú, A. (2009). Violencias y discriminaciones en las ciudades. En A. Falú (Ed.), Mujeres en la ciudad. De violencias y derechos (pp. 15-38). Santiago, Chile: LOM Ediciones.

Faur, E. (2004). Masculinidades y desarrollo social. Las relaciones de género desde la perspectiva de los hombres. Bogotá, Colombia: Arango Editores Ltda.

Karsten, L. y Meertens, D. (1991-1992). La geografía del género: sobre visibilidad, identidad y relaciones de poder. Documents d'Análisi Geografica, (19-20), 181-193. 
Lainez, Z. (2013). ¡Ayayay mamita rica! Recuperado de http://www.plazapublica. com.gt/content/ayayay-mamita-rica

List, M. (2007). Masculinidades urbanas. Una reflexión a partir de algunos ejemplos de la ciudad de Puebla. En M. Portal (Coord.), Espacios públicos y prácticas metropolitanas (pp. 177-206). México D.F., México: Soluciones de Comunicación S.C.

Medellín te espera. (2015). Mapa de Medellín-Colombia-Barrios y comunas. Recuperado de http://medellintespera.blogspot.com.co/p/mapa-de-medellincon-barrios-y-comunas.html

Monk, J. y Hanson, S. (1989). Temas de geografía feminista contemporánea. Documents d'analisi geográfica, (14), 31-50.

Niño, S. (2000). Territorios del miedo en Santafé de Bogotá. Imaginarios de sus ciudadanos. Desde la Región, (31), 38-46.

Páramo, P. y Burbano, A. (2011). Género y espacialidad: análisis de factores que condicionan la equidad en el espacio público urbano. Universitas Psychologica, 10(1), 61-70.

Reguillo, R. (1998, septiembre 11-16). Imaginarios globales, miedos locales: la construcción social del miedo en la ciudad. Ponencia presentada en el IV Encuentro de la Asociación Latinoamericana de Investigadores de la Comunicación. ALAIC. "Ciencias de la Comunicación: Identidades y Fronteras". Universidad Católica de Pernambuco, Recife, Brasil.

Reguillo, R. (2000). Imaginarios globales, miedos locales: la construcción social del miedo en la ciudad. En S. Rotker (Ed.), Ciudadanías del miedo (pp. 17-26). Caracas, Venezuela: Nueva Sociedad.

Román, M. (2009). Recuperar la confianza, recuperar la ciudad. En A. Falú (Ed.), Mujeres en la ciudad. De violencias y derechos (pp. 137-144). Santiago, Chile: LOM Ediciones.

Toro, J. (Dirección). (2015). Mujeres, a la calle (documental). Colombia: Señal Colombia, Usaid.

Toro, J. y Ochoa, M. (2015). Mujeres, a la calle: Configuraciones urbanas, violencia y roles de género; un análisis de las violencias hacia las mujeres en espacios públicos de Medellín (tesis de pregrado). Universidad de Antioquia, Medellín, Colombia. 